Objectives: To describe the characteristics and differences between patients with primary LVV and LVV associated with GCA in a single center.

Methods: Retrospective study of patients with LVV in a University Hospital (January 2013-December 2018). Patients diagnosed with aortitis using an imaging test (PET-CT/angioCT/CT/MRI) were included. GCA was diagnosed by biopsy and/or ultrasound of the temporal artery. The primary LVV was considered by exclusion of inflammatory or infectious causes. Epidemiological, clinical and analytical variables, affected vascular territories and the treatment received in both groups were reviewed.

Frequencies and percentages were used in qualitative variables, mean $\pm S D$ in quantitative and for the comparison between groups Chi2 test or Fisher test was used in categorical variables and Student $T$ test or $U$ of Mann-Whitney in quantitative. The statistical analysis was performed with IBM SPSS v.23.

TABLE 1. CHARACTERISTICS OF PRIMARY LVV AND LVV ASSOCIATED WITH GCA.

\begin{tabular}{|c|c|c|c|}
\hline & $\begin{array}{c}\text { Primary LVV, } \\
\mathrm{n}=15\end{array}$ & $\begin{array}{l}\text { LVV associated } \\
\text { with GCA, } n=13\end{array}$ & $\mathbf{P}$ \\
\hline Age, mean $\pm S D$ & $66.33 \pm 10.16$ & $76.77 \pm 8.9$ & $0.004^{*}$ \\
\hline Age $\geq 70$ years, $n(\%)$ & $8(53.3 \%)$ & $10(76.9 \%)$ & 0.254 \\
\hline $\operatorname{Sex}(M / F)$ & $4 / 11$ & $3 / 10$ & 1 \\
\hline \multicolumn{4}{|l|}{ VASCULAR RISK FACTORS } \\
\hline High blood pressure, $\mathrm{n}(\%)$ & $3(20 \%)$ & $7(53.8 \%)$ & 0.114 \\
\hline Diabetes, $\mathrm{n}(\%)$ & $2(13.3 \%)$ & $0(0 \%)$ & 0.484 \\
\hline Dyslipidemia, $n(\%)$ & $4(26.7 \%)$ & $5(38.5 \%)$ & 0.689 \\
\hline Tobacco, (\%) & $2(13.3 \%)$ & $3(23.1 \%)$ & 0.598 \\
\hline \multicolumn{4}{|l|}{ CLINICAL FEATURES AT AORTITIS DX } \\
\hline Constitutional syndrome, $n(\%)$ & $10(66.7 \%)$ & $9(69.2 \%)$ & 1 \\
\hline Fever, $\mathrm{n}(\%)$ & $6(40 \%)$ & $2(15.4 \%)$ & 0.221 \\
\hline Atypical PmR, n (\%) & $10(66.7 \%)$ & $6(46.2 \%)$ & 0.274 \\
\hline Inflammatory low back pain, $n(\%)$ & $7(46.7 \%)$ & $1(7.7 \%)$ & $0.038^{*}$ \\
\hline Irradiated lower limb pain, $\mathrm{n}(\%)$ & $2(13.3 \%)$ & $2(15.4 \%)$ & 1 \\
\hline \multicolumn{4}{|l|}{ LABORATORY TEST AT AORTITIS DX } \\
\hline Hemoglobin, mean \pm SD & $12.07 \pm 1.85$ & $11.1 \pm 1.13$ & 0.108 \\
\hline Platelets, mean \pm SD & $310013 \pm 112683$ & $308538 \pm 80075$ & 0.751 \\
\hline $\mathrm{CRP}$, mean $\pm \mathrm{SD}$ & $2.94 \pm 1.94$ & $5.52 \pm 5.7$ & 0.118 \\
\hline ESR, mean $\pm S D$ & $70.2 \pm 31.02$ & $65.31 \pm 23.79$ & 0.683 \\
\hline \multicolumn{4}{|l|}{ AFFECTED TERRITORIES } \\
\hline Superior limbs, $n(\%)$ & $1(6.7 \%)$ & $1(7.7 \%)$ & 1 \\
\hline Supra-aortic trunks, n (\%) & $10(66.7 \%)$ & $10(76.9 \%)$ & 0.686 \\
\hline Aortic arch, $n(\%)$ & $11(73.3 \%)$ & $7(53.8 \%)$ & 0.433 \\
\hline Thoracic aorta, n (\%) & $11(73.3 \%)$ & $12(92.3 \%)$ & 0.333 \\
\hline Abdominal aorta, $\mathrm{n}(\%)$ & $10(66.7 \%)$ & $6(46.2 \%)$ & 0.445 \\
\hline lliac arteries, $\mathrm{n}(\%)$ & $1(6.7 \%)$ & $4(30.8 \%)$ & 0.153 \\
\hline Femoropopliteal arteries, $\mathrm{n}(\%)$ & $1(6.7 \%)$ & $2(15.4 \%)$ & 0.583 \\
\hline \multicolumn{4}{|l|}{ TREATMENT OF AORTITIS AT DX } \\
\hline Prednisone dose (mg/day), mean $\pm \mathrm{SD}$ & $44.33 \pm 17.2$ & $38.46 \pm 17.8$ & 0.387 \\
\hline Patients receiving CS pulses, $\mathrm{n}(\%)$ & $4(26.7 \%)$ & $3(23 \%)$ & 0.827 \\
\hline Patients receiving MTX, $n$ (\%) & $8(53.3 \%)$ & $10(76.9 \%)$ & 0.184 \\
\hline MTX dose ( $\mathrm{mg} /$ week), mean $\pm \mathrm{SD}$ & $12.81 \pm 4.1$ & $11.25 \pm 3.58$ & 0.460 \\
\hline Patients receiving biololgical therapy, $\mathrm{n}(\%)$ & $0(0 \%)$ & $2(15.4 \%)$ & 0.206 \\
\hline \multicolumn{4}{|l|}{ EVOLUTION AT 4 MONTHS } \\
\hline Asymptomatic/partial improvement/no change, $n$ & $8 / 6 / 1$ & $7 / 5 / 1$ & 0.993 \\
\hline Prednisone dose (mg/day), mean \pm SD & $16.5 \pm 8.1$ & $20.2 \pm 8.06$ & 0.254 \\
\hline Patients receiving MTX, $\mathrm{n}(\%)$ & $12(80 \%)$ & $11(84.6 \%)$ & 1 \\
\hline MTX dose (mg/week), mean \pm SD & $15.83 \pm 5.6$ & $12.05 \pm 4.3$ & 0.091 \\
\hline Patients receiving biololgical therapy, $\mathrm{n}(\%)$ & $1(6.7 \%)$ & $2(15.4 \%)$ & 0.583 \\
\hline CRP, mean $\pm S D$ & $0.84 \pm 2.12$ & $0.59 \pm 0.82$ & 0.698 \\
\hline$E S R$, mean $\pm S D$ & $23.4 \pm 27$ & $18.7 \pm 19.1$ & 0.609 \\
\hline Hemoglobin, mean \pm SD & $13.45 \pm 1.53$ & $12.75 \pm 1.43$ & 0.230 \\
\hline
\end{tabular}

LVV: large vessel vasculitis, GCA: giant cell arteritis, DX: diagnosis, PmR: polymyalgia rheumatic, CPR: C-reactive protein,
Results: We included 28 patients diagnosed with LVV (9 between 20132015 and 19 between 2016-2018). 75\% were female with an average age $\pm S D$ of $71.18 \pm 10.8$ years. They were divided into two groups: primary LVV $(n=15)$ and LVV associated with GCA $(n=13)$. The diagnosis of GCA was made by ultrasound $(n=6)$, biopsy $(n=5)$ and both tests $(n=2)$. In 7 patients $(54 \%)$ aortitis and GCA diagnosis was simultaneous. In LVV with GCA, headache was observed in $84.6 \%$ of patients and constitutional syndrome in $53.8 \%$.

Primary LVV was characterized by lower age at onset, inflammatory low back pain, fever, atypical polymyalgia rheumatica and lower CRP levels; only the first two variables reached statistical significance, probably due to sample size. TABLE 1

The mean number of affected vascular territories was 3 and thoracic aorta was the most affected territory in both groups.

The steroid treatment was similar in both groups, whereas methotrexate (MTX) was used more frequently in the LVV associated with GCA. In the first 4 months, 1 patient with primary LVV required Tocilizumab (TCZ).

The final clinical evolution was similar and favorable in both groups. At the last visit, after a mean follow-up of $11.94 \pm 8.5$ months in the primary LVV and $29.63 \pm 14.8$ months in the LVV secondary to GCA, $93 \%$ of patients were asymptomatic with a mean ESR of $24,07 \pm 20$ and CRP
$0.56 \pm 0.91$. Treatment used in primary LVV were: glucocorticoids (CS) $(n=4)$, mean dose $8.75 \pm 7.4 \mathrm{mg}$; MTX ( $n=11)$, mean dose $18.18 \pm 5.6 \mathrm{mg} /$ week and TCZ $(n=2)$. In LVV associated with GCA, 2 patients were without treatment; CS $(n=9)$, mean dose $4.75 \pm 4 m g ; \operatorname{MTX}(n=8)$, mean dose $13.44 \pm 6 \mathrm{mg} /$ week and TCZ $(n=2)$.

15 imaging tests were performed 6-10 months after diagnosis. Later, after an average time of $28.77 \pm 10.7$ months 9 more control PET-CT were requested. TABLE 2.

TABLE 2. EVOLUTION OF IMAGE TESTS PERFORMED.

\begin{tabular}{|l|c|c|c|}
\cline { 2 - 4 } \multicolumn{1}{c|}{} & \multicolumn{1}{c|}{$\begin{array}{c}\text { Primary LVV, } \\
\mathrm{n}=\mathbf{1 5}\end{array}$} & $\begin{array}{c}\text { LVV associated } \\
\text { with GCA, } \mathrm{n}=13\end{array}$ & TOTAL=28 \\
\hline $\begin{array}{l}\text { AT 6-10 MONTHS, } \\
\text { (total of tests performed, } \mathrm{n} \text { ) }\end{array}$ & $\mathbf{6}$ & 9 & 15 \\
\hline Full resolution, $\mathrm{n}(\%)$ & $0(0 \%)$ & $2(22.2 \%)$ & $2(13.3 \%)$ \\
\hline Partial improvement, $\mathrm{n}(\%)$ & $5(83.3 \%)$ & $4(44.4 \%)$ & $9(60 \%)$ \\
\hline Without changes, $\mathrm{n}(\%)$ & $1(16.7 \%)$ & $2(22.2 \%)$ & $3(20 \%)$ \\
\hline Worsening, $\mathrm{n}(\%)$ & $0(0 \%)$ & $1(11.1 \%)$ & $1(6.7 \%)$ \\
\hline LAST PET-CT, $(\mathrm{n})$ & 3 & 6 & 9 \\
\hline $\begin{array}{l}\text { Time of evolution } \\
\text { (months, meant5D) }\end{array}$ & $22.67 \pm 7.51$ & $31.83 \pm 11.29$ & $28.77 \pm 10.7$ \\
\hline Full resolution, $\mathrm{n}(\%)$ & $1(33.3 \%)$ & $0(0 \%)$ & $1(11.1 \%)$ \\
\hline Partial improvement, $\mathrm{n}(\%)$ & $0(0 \%)$ & $2(33.3 \%)$ & $2(22.2 \%)$ \\
\hline Without changes, $\mathrm{n}(\%)$ & $1(33.3 \%)$ & $3(50 \%)$ & $4(44 \%)$ \\
\hline Worsening, $\mathrm{n}(\%)$ & $1(33.3 \%)$ & $1(16.7 \%)$ & $2(22.2 \%)$ \\
\hline
\end{tabular}

Conclusion: In this study, younger age at onset and inflammatory low back pain were more frequent in primary LVV with statistical significance. The most affected vascular territory was the thoracic aorta in both groups.

The clinical and analytical evolution was similar in both populations. In the treatment, the only notable thing was the increased use of MTX in the LVV associated with GCA.

$68 \%$ of the aortitis were diagnosed in the last 3 years due to greater clinical suspicion. PET-CT is a useful tool in the diagnosis of this pathology.

Disclosure of Interests: None declared

DOI: 10.1136/annrheumdis-2019-eular.4694

\section{AB0579 COMPARISON OF CLINICAL CHARACTERISTICS OF EOSINOPHILIC GRANULOMATOSIS WITH POLYANGIITIS BETWEEN RHEUMATOLOGY AND RESPIRATORY MEDICINE: A SINGLE CENTER, RETROSPECTIVE STUDY}

Le-Feng Chen, LI Qianhua, Dong-Hui Zheng, Lie Dai. Sun Yat-Sen Memorial Hospital, Sun Yat-Sen University, Department of Rheumatology, Guangzhou, China

Background: Eosinophilic granulomatosis with polyangiitis (EGPA) is a rare but potentially life-threatening systemic necrotizing vasculitis. Multiple organs may be involved and patients initial consulting different departments may have different clinical manifestations.

Objectives: To explore the clinical characteristic of EGPA diagnosed in different departments in our hospital.

Methods: A retrospective study of EGPA patients in Sun Yat-Sen Memorial Hospital, Sun Yat-Sen University, Guangzhou, China. All patients fulfill the ACR 1990 classification criteria or the EULAR/ACR 2017 draft classification criteria. Demographic and clinical data of EGPA patients were collected and compared between different departments.

Results: 1) There were 45 EGPA patients diagnosed between December 2003 and January 2019. There were 29(64.4\%) male, with median onset age 46(36 56) years, median time required for diagnosis 24(3 96) months. There were $8(17.8 \%)$ patients had history of drug allergy. There were $31(68.9 \%)$ patients fulfill the ACR 1990 classification criteria and 40 (88.9\%) fulfill the EULAR/ACR 2017 draft classification criteria.

2) The main clinical manifestations included asthma-like symptoms $(82.2 \%)$, limb numbness $(37.8 \%)$, rash $(22.2 \%)$, fever $(20.0 \%)$, gastrointestinal symptom $(11.1 \%)$ and arthralgias $(8.9 \%)$. There were $91.1 \%(41 / 45)$ patients had serum eosinophil $>10 \%, 77.8 \%$ (35/45) serum eosinophil $>1.0 \times 10^{9} / \mathrm{L}, \quad 77.5 \% \quad(31 / 40)$ elevated serum $\operatorname{lgE}, 7.8 \%$ (3/44) positive MPO-ANCA or p-ANCA and $18.4 \%(7 / 38)$ positive ANA.

3) There were $21(46.7 \%)$ patients diagnosed at rheumatology, $22(48.9 \%)$ at respiratory medicine, $1(2.2 \%)$ at dermatology and $1(2.2 \%)$ at pediatrics. 
Compared with patients diagnosed at respiratory medicine, patients diagnosed at rheumatology had a higher frequency of fever $(33.3 \%$ vs. 0$)$, rash $(33.3 \%$ vs. $4.5 \%)$, arthralgias $(19.0 \%$ vs. 0$)$ and limb numbness $(57.1 \%$ vs. $22.7 \%)$, but lower frequency of asthma-like symptoms $(66.7 \%$ vs. $100 \%$; all $P<0.05)$. There were more patients diagnosed at rheumatology received treatment of glucocorticoid (100\% vs. $72.7 \%)$, immunosuppressive agents $(85.7 \%$ vs. $4.5 \%)$ and intravenous immunoglobin $(28.6 \%$ vs. 0 ) than those diagnosed at respiratory medicine (all $P<0.01$ ). Patients diagnosed at rheumatology also received higher initial dose of glucocorticoid than those diagnosed at respiratory medicine [50(50 100) $\mathrm{mg} / \mathrm{d}$ vs. 28(10 40) $\mathrm{mg} / \mathrm{d}$ of prednisone dosage, $P<0.001]$.

4) Among the 21 patients diagnosed at rheumatology, 14(66.7\%) had asthma-like symptoms, who showed significant longer time required for diagnosis than those without asthma-like symptoms [36(24 120) months vs. 2(2 13) months, $P=0.020]$, but showed no significant difference of onset age between these two groups ( $P>0.05)$.

5) The median revisited Five-Factor Score (FFS) was $0(0 \sim 1)$. There were $17(37.8 \%)$ patients had $F F S \geq 1$, who had older diagnostic age than those with $\mathrm{FFS}=0$ [65(46 68) years vs. 48(42 53) years, $P<0.05]$, but with no significant difference of onset age or time required for diagnosis. Patients with $F F S \geq 1$ had higher level of serum $\operatorname{lgE}[1280(515 \sim 4895) \quad \mathrm{IU} / \mathrm{mL}$ vs. 243(72 587) $\mathrm{IU} / \mathrm{mL}]$ than those with $\mathrm{FFS}=0 \quad(P<0.05)$.

Conclusion: Clinical manifestations of EGPA were different between rheumatology and respiratory medicine. Rheumatologist may be more aggressive treating EGPA patients with glucocorticoid and immunosuppressive agents than respiratory physician. Multidisciplinary team is needed for the diagnosis and management of EGPA.

Acknowledgement: This work was supported by Guangdong Medical Scientific Research Foundation (grant no. A2017093) to Le-Feng Chen. Disclosure of Interests: None declared

DOI: 10.1136/annrheumdis-2019-eular.5369

\section{\begin{tabular}{|l|l} 
AB0580 & A VISION OF THE CHARACTERISTICS AND
\end{tabular} COMORBIDITIES OF GIANT CELL ARTERITIS FROM THE HOSPITAL RECORDS OF THE NATIONAL HEALTH SYSTEM}

Carmen de Frutos Fernández ${ }^{1}$, Maria Angeles Martinez Huedo ${ }^{2}$, Irene Monjo ${ }^{3}$, Eugenio de Miguel| ${ }^{3}$. 1 Medicine Student Universidad Autónoma de Madrid. Rheumatology service, Hospital Universitario la Paz-IdiPaz., Madrid, Spain; ${ }^{2} U$. Docencia e Investigación. Hospital Universitario La Paz. Madrid., Madrid, Spain; ${ }^{3}$ Rheumatology service, Hospital Universitario la Paz-IdiPaz., Madrid, Spain

Background: Gigant cell arteritis (GCA) is the most frequent systemic vasculitis in older than 50 years old, with serious repercussions on the quality of life and survival of patients. The low prevalence and heterogeneous presentation make progress in the diagnostic and the knowledge of the disease difficult.

Objectives: The objective of this study has been to gather a large database to analyze the epidemiological characteristics, the comorbidities and the causes of mortality associated with the hospitalizations by ACG in our country.

Methods: Retrospective observational study based on data from the Database of Hospital from the Spanish National Health Service with primary or secondary diagnostic of GCA between January $1^{\text {st }}, 2005$ and December 31th, 2015. The included variables were sex, age, main reason for admission, secondaries diagnostics, time of stay, costs, comorbidities, temporal artery biopsy and mortality.

Results: The study cohort included 29.576 patients with GCA, 18.568 $(62,8 \%)$ women, and the mean age was $80 \pm 8$ years. The number of hospital admissions with this diagnostic has increased between 2008 and 2013 with an annual cumulative increase rate of $3 \%$, passing from 2.487 to 2.997 patients/year. We have found a different disease affectation pattern in men and women in terms of distribution by age group and the comorbidities associated. We have found that the mortality risk increases with the age and with the presence of cardiovascular disease OR 1,816 $(1,484-2,221)$, ischemic heart disease OR $1,590(1,302-1,941)$, renal disease OR 1,386 (1,225-1,569) and cancer OR 2,428 (2,039-2,891). While, a decrease in the risk of death was observed in patients who associated polymyalgia rheumatica OR $0.682(0,5810,801)$.

Table 1. Comorbidities and mortality in hospitalized with ACG

\begin{tabular}{lcccccc}
\hline & \multicolumn{2}{c}{ Men } & \multicolumn{2}{c}{ Woman } & \multicolumn{2}{c}{ Both sexes } \\
\hline & $\mathrm{N}$ & $\%$ & $\mathrm{~N}$ & $\%$ & $\mathrm{~N}$ & $\%$ \\
\hline DM2 $^{*}$ & 2948 & $26,8 \%$ & 4669 & $25,1 \%$ & 7617 & $25,8 \%$ \\
PMR $^{*}$ & 1474 & $13,4 \%$ & 2715 & $14,6 \%$ & 4189 & $14,2 \%$ \\
ICC $^{*}$ & 1298 & $11,8 \%$ & 2854 & $15,4 \%$ & 4152 & $14 \%$
\end{tabular}

\begin{tabular}{|c|c|c|c|c|c|c|c|}
\hline \multicolumn{8}{|l|}{$\begin{array}{l}\text { ENF. } \\
\text { RENAL * }\end{array}$} \\
\hline Cancer & & 809 & $7,3 \%$ & 499 & $2,7 \%$ & 1308 & $4,4 \%$ \\
\hline IHD * & & 626 & $5,7 \%$ & 565 & $3,0 \%$ & 1191 & $4 \%$ \\
\hline ECV * & & 502 & $4,6 \%$ & 651 & $3,5 \%$ & 1153 & $3,9 \%$ \\
\hline EPOC & & 289 & $2,6 \%$ & 559 & $3,0 \%$ & 848 & $2,9 \%$ \\
\hline \multirow[t]{3}{*}{$\mathrm{CCl}^{\star}$} & $\begin{array}{c}\text { No } \\
\text { comorbidities }\end{array}$ & 4833 & $43,9 \%$ & 9174 & $49,4 \%$ & 14008 & $47,4 \%$ \\
\hline & $\begin{array}{l}\leq 2 \\
\text { Comorbidities }\end{array}$ & 5635 & $51,2 \%$ & 8697 & $46,8 \%$ & 14332 & $48,5 \%$ \\
\hline & $\begin{array}{l}>2 \\
\text { Comorbidities }\end{array}$ & 539 & $4,9 \%$ & 697 & $3,8 \%$ & 1236 & $4,2 \%$ \\
\hline Mortality & & 712 & $6,5 \%$ & 1083 & $5,8 \%$ & 1795 & $6,1 \%$ \\
\hline
\end{tabular}

*Statistically significant differences $(P<0.05)$ DM2: Diabetes mellitus Type 2 PMR: Polymyalgia rheumatica ICC: Congestive heart failure IHC: ischemic heart disease ECV: Cerebrovascular disease $\mathbf{C C I}$ : Charlson Index of Comorbidities Conclusion: In recent years the number of GCA hospital admissions has increased. The presence of comorbidities is high and greater in men. An increase in deaths for ischemic cause and a reduction of mortality in patients with PMR associated is observed

Disclosure of Interests: None declared

DOI: 10.1136/annrheumdis-2019-eular.3246

\section{AB0581 AN ATYPICAL PRESENTATION OF GIANT CELL ARTERITIS WITH SCALP LUMPS: A CASE REPORT}

Uthpala Dissanayake, Risniya Hassan. District General Hospital, Kegalle, Sri Lanka

Background: Giant cell arteritis (GCA) also referred as temporal arteritis is a systemic inflammatory vasculitis of unknown etiology which can result in wide range of systemic, neurologic and ophthalmic complications. It predominantly occurs in older people and may be associated with Polymyalgia Rheumatica. It must be treated urgently as it is associated with significant risk of permanent visual loss, stroke, aneurysm and possible death. Diagnosis of GCA can be based on clinical findings such as headache, scalp tenderness, jaw claudication and temporal artery problems, an elevated ESR and biopsy temporal artery showing typical histopathological findings. Diagnosis of GCA may be delayed when presentation is atypical.

Objectives: We report a case of an elderly lady presenting with scalp lump as an unusual presentation of GCA.

Methods: 70 years old lady presented with multiple painful scalp lumps to the surgeon was referred to the Rheumatologist when the excision biopsy of the lump diagnosed the GCA. (Sub cutis medium sized artery with severe arteritis composed with lymphocytes, neutrophils and occasional Eosinophills). On enquiry she revealed a history of generalized malaise and lethargy at the outset of the illness preceded by jaw pain She had been initially referred to the dental surgeon which resulted in multiple carious tooth extractions without a relief. She didn't have any eye symptoms or headache at the outset. She lately developed headache and pain on touching the lumps.

On examination she had bilateral hardened thickened palpable non pulsa tile temporal arteries. Her scalp was tender with multiple small cystic lumps. Her ESR was highly elevated $141 \mathrm{~mm} / \mathrm{hr}$. WBC $9.7, \mathrm{Hb} 9.5$ and PLT 283. Her ANA, liver and renal profiles were normal. Her BL Doppler USS was consistent with BL temporal arteritis.

Results: She was soon started on high dose prednisolone with low dose aspirin which improved her systemic symptoms along with inflammatory markers significantly over a few days. She was referred for eye assessment and the involvement of other systemic larger arteries was ruled out Conclusion: Most of the cases the diagnosis of GCA is obvious but in patients with uncommon clinical presentation the diagnosis may be difficult.GCA is classified as disease of large vessel vasculitis but typically also involves medium and small arteries. The granulomatous inflammation in the vessel wall leads to obstruction of the lumen and ischemia in the territory distal to it. GCA involves almost all speciality and it is associated with increased mobility and mortality if not diagnosed and treated early. Awareness of rare presentation of GCA avoids unnecessary investigation and delaying the treatment.If there is no rapid improvement of symptoms within few weeks of starting treatment other diagnosis should be considered. 